\title{
Spatial variations of $P$ wave attenuation in the mantle beneath North America
}

\author{
Yong Keun Hwang, ${ }^{1}$ Jeroen Ritsema, ${ }^{1}$ and Saskia Goes ${ }^{2}$ \\ Received 10 September 2008; revised 26 February 2009; accepted 17 April 2009; published 20 June 2009.
}

[1] We estimate the spatial variation of the seismic parameter $t^{*}$ using teleseismic (epicentral distance $\left.=30^{\circ}-85^{\circ}\right) P$ wave spectra of about 200 deep (focal depths $>200 \mathrm{~km}$ ) earthquakes recorded by 378 broadband seismometers in the United States and Canada. Relative $P$ wave spectral ratios up to $1 \mathrm{~Hz}$ for about 63,000 station pairs with high signal-to-noise ratio and impulsive $P$ waveforms are inverted for $t_{P}^{*}$ by least squares inversion. The continental-scale $t_{P}^{*}$ pattern correlates to the age of geological terrains and the seismic, heat flow, gravity, and magnetic variations across North America.

Predominantly low values of $t_{P}^{*}$ are obtained in stable central North America (SNA), and high $t_{P}^{*}$ values are obtained for stations in the tectonically active western part of the continent (TNA). This variation is similar to that observed previously in short-period amplitude anomalies, spectral ratio variations, and $\mathrm{ScS}$ reverberations. On average, we resolve a contrast in $t_{P}^{*}$ between SNA and TNA of about $0.2 \mathrm{~s}$. We resolve regional variations in $t_{P}^{*}$, which correlate with tectonics. Relatively low $t_{P}^{*}$ is associated with currently active subduction below Alaska. Relatively high $t_{P}^{*}$ is found in SNA below the Appalachians and the Gulf Coast. The consistency between $t_{P}^{*}$ and tectonics suggests that the observed variations in $t_{P}^{*}$ are, on the scale of around $200-500 \mathrm{~km}$, predominantly due to intrinsic attenuation. The similar patterns in $t_{P}^{*}$ and predicted values for a recent global attenuation model confirm this further. The compatibility with the $t_{P}^{*}$ computed for attenuation estimated via a thermal interpretation of shear wave velocity anomalies illustrates that variations in seismic velocity are predominantly due to physical effects with a strong attenuation signature, most likely temperature or a combination of temperature and water content.

Citation: Hwang, Y. K., J. Ritsema, and S. Goes (2009), Spatial variations of P wave attenuation in the mantle beneath North America, J. Geophys. Res., 114, B06312, doi:10.1029/2008JB006091.

\section{Introduction}

[2] Models of seismic attenuation provide important constraints on the physical state of Earth's interior. Seismic wave attenuation and velocity dispersion [Kanamori and Anderson, 1977] are affected by temperature, by volatiles, and, depending on the dominant relaxation mechanism, by the presence of melt [Sato et al., 1989; Hammond and Humphreys, 2000; Faul and Jackson, 2005]. Moreover, anelasticity provides one of the few available measures of rheology at lithosphere and mantle conditions, albeit on seismic timescales [Karato and Spetzler, 1990; Jackson et al., 2002].

[3] Attenuation constraints are key in the interpretation of models of seismic velocity (i.e., seismic tomography) [Sobolev et al., 1996; Goes et al., 2000; Goes and van

\footnotetext{
${ }^{1}$ Department of Geological Sciences, University of Michigan, Ann Arbor, Michigan, USA.

${ }^{2}$ Department of Earth Science and Engineering, Imperial College London, London, UK.

Copyright 2009 by the American Geophysical Union. 0148-0227/09/2008JB006091\$09.00
}

der Lee, 2002; Lee, 2003; Godey et al., 2004; Shapiro and Ritzwoller, 2004; Faul and Jackson, 2005; Deen et al., 2006; Schutt and Lesher, 2006]. These studies demonstrate that velocity variations in the uppermost mantle $(<200-$ $300 \mathrm{~km}$ ) are primarily due to temperature variations because of the high temperature sensitivity to anelastic effects in this depth range [Sato et al., 1989; Karato, 1993; Goes et al., 2000; Jackson et al., 2002; Faul and Jackson, 2005]. Variations in major element chemistry have a non-negligible contribution on velocity anomalies only in the coldest regions of the uppermost mantle, which can be resolved in combination with density-sensitive data [Perry et al., 2003; Godey et al., 2004; Deen et al., 2006]. However, the interpretation of tomographic models is meaningful only when constraints on attenuation with comparable spatial resolution are available.

[4] On a global scale, tomographic images reveal seismic velocity structures that are only a few hundred kilometers in size [Romanowicz, 2008]. Global attenuation models are still designed to constrain long wavelength variations because the effects of intrinsic attenuation on wave amplitudes cannot be easily distinguished from the effects of wave scattering, focusing, and crustal amplification in a perfectly 
elastic but heterogeneous Earth. Global attenuation models based on surface waves [Romanowicz, 1995; Billien et al., 2000; Romanowicz and Gung, 2002; Selby and Woodhouse, 2002; Dalton and Ekström, 2006], body waves [Bhattacharyya et al., 1996; Reid et al., 2001; Warren and Shearer, 2002; Lawrence and Wysession, 2006], and $L g$ coda [Mitchell and Cong, 1998] share similar large-scale features that correlate with the seismic velocity structures. However, it is well appreciated that, because of the strong influence of focusing effects, global attenuation models are strongly damped and that they may underestimate the peakto-peak variation in attenuation within various regions. It is therefore difficult to determine whether the elastic and anelastic seismic structures in the shallow mantle have a common physical origin.

[5] In this study we analyze attenuation in the upper mantle using broadband teleseismic (epicentral distance $=$ $\left.30^{\circ}-85^{\circ}\right) P$ wave spectra of deep earthquakes. We focus on the North American continent. Here resolution is relatively high because of the dense station coverage offered by the various regional seismic networks. Moreover, we expect large variations in attenuation in North America due to its diverse tectonic terrains, facilitating a comparison of models obtained from a variety of data types.

[6] We compare our results to the most recent global surface wave attenuation model [Dalton et al., 2008] and an attenuation model inferred from a thermal conversion of a regional shear velocity model [Goes and van der Lee, 2002]. This allows us to place our results in a global context, to determine the compatibility of the body wave and surface wave attenuation constraints, and to evaluate whether a thermal interpretation of shear velocity variation and attenuation is justified.

\section{Seismic Wave Attenuation in North America}

[7] The Rocky Mountain Front divides North America into tectonic western North America (TNA) and stable eastern North America (SNA). TNA is associated with current extension in the Basin and Range, subduction under Oregon and Washington continued to transform motion in California, and volcanism in Yellowstone and western Rocky Mountain front [Burchfiel et al., 1992; Humphreys and Coblentz, 2007]. In contrast, the most recent tectonic event in SNA is related to the Appalachian orogeny (330$265 \mathrm{Ma}$ ) [Dallmeyer et al., 1986; Secor et al., 1986].

[8] Geophysical studies of the upper mantle and the lithosphere indicate that a structural divide between TNA and SNA persists in the mantle. High surface heat flow, low-amplitude magnetic anomalies, and a negative long wavelength Bouguer gravity in TNA indicate that the mantle below TNA is hot while low surface heat flow and short wavelength magnetic and gravity anomalies indicate a cool lithosphere mantle below SNA [Morgan and Gosnold, 1989]. Studies of body wave traveltime [Grand and Helmberger, 1984; Melbourne and Helmberger, 1998] and surface wave dispersion [Van der Lee and Nolet, 1997; Marone and Romanowicz, 2007] show that the shear velocity in the upper mantle beneath SNA and TNA differs by as much as $15-20 \%$.

[9] A large number of studies have provided constraints on the attenuation structure in North America, including analyses of short-period amplitude anomalies [Cleary, 1967; Booth et al., 1974; Butler and Ruff, 1980; Der et al., 1982; Butler, 1984], spectral ratio variations [Solomon and Toksöz, 1970; Der and McElfresh, 1976, 1977; Der et al., 1982], Lg coda waves [Baqer and Mitchell, 1998], and ScS multiples [Lay and Wallace, 1988]. The studies show a common first-order pattern of a highly attenuating TNA and low-attenuation SNA. In addition, the regional studies indicate that smaller-scale $(<1000 \mathrm{~km})$ variations of attenuation can be as large as the continental-scale contrast between TNA and SNA. Lay and Wallace [1988], for example, suggest that shear wave attenuation in the upper mantle beneath the Basin and Range, a region with extremely high heat flow, is as strong as attenuation beneath active mid-ocean ridge spreading centers and that attenuation beneath the Pacific Northwest is comparable to attenuation within western Pacific subduction zones.

\section{P Wave Spectral Analysis}

[10] In addition to the geometric spreading of wavefronts, seismic waves are attenuated by anelastic energy dissipation and scattering. The efficiency of wave propagation is commonly expressed by the quality factor $Q$. Its inverse, $Q^{-1}$, quantifies wave attenuation. $Q^{-1}$ is defined as

$$
Q^{-1}=\Delta E / 2 \pi E_{\max }
$$

where $\Delta E$ is the energy lost per cycle and $E_{\max }$ is the maximum elastic energy contained in a cycle.

[11] The attenuation of teleseismic body waves is defined by the attenuation parameter $t^{*}$. The $t^{*}$ parameter is a station-specific observable that represents the total body wave traveltime divided by $Q$ along the raypath [Stein and Wysession, 2003]:

$$
t^{*}=\int_{r a y} \frac{1}{V(r) Q(r)} d s
$$

Typically, $t_{P}^{*}=1 \mathrm{~s}$ for teleseismic $P$ waves and $t_{S}^{*}=4 \mathrm{~s}$ for teleseismic $S$ waves [Cormier, 1982]. These values vary little with epicentral distance [Booth et al., 1974] suggesting that body waves are attenuated primarily in the upper mantle. This observation is consistent with one-dimensional profiles derived from long-period surface waves and normal modes [Dziewonski and Anderson, 1981; Durek and Ekström, 1996] which show that $Q$ values in the upper mantle are an order of magnitude lower than in the lower mantle.

[12] In this study, we measure $t_{P}^{*}$ from teleseismic $P$ wave spectra. $t_{P}^{*}$ encompasses multiple effects: intrinsic attenuation, crustal amplification, focusing and defocusing, and local scattering in the upper mantle under the receiver. Probably, each of these factors is equally important given the large scatter seen in measurements of $t_{P}^{*}$. To isolate the contribution of intrinsic attenuation to $t_{P}^{*}$, we rely on a large and redundant set of $P$ wave spectra for earthquake/receiver combinations over a wide range of azimuths. 


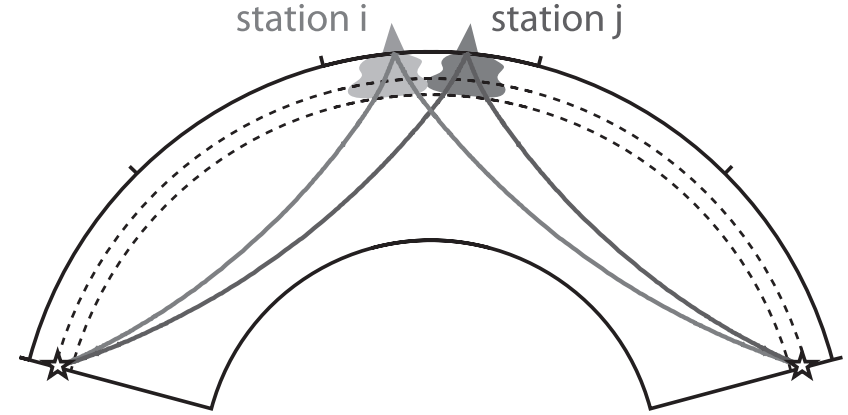

Figure 1. Geometrical raypaths of $P$ waves propagating from deep earthquake sources (stars) to stations at teleseismic distances (triangles).

\subsection{Teleseismic $P$ Wave Spectra}

[13] We follow the classical approach developed by Teng [1968] and Solomon and Toksöz [1970]. We write the spectrum $O(f)$ of a teleseismic seismogram as

$$
O(f)=S(f) \exp \left(-\pi f t_{P}^{*}\right),
$$

where $S(f)$ is the earthquake source spectrum and $\exp \left(-\pi f t_{P}^{*}\right)$ is the attenuation function. The logarithm of the ratio $R_{i j}$ between the spectrum $O_{i}$ and $O_{j}$ at stations $i$ and $j$ is expected to change linearly with frequency $f$ for the same earthquake:

$$
\ln R_{i j}(f)=-\pi f \Delta t_{P} *_{i j}
$$

$\Delta t_{P}^{*}$ reflect differences in $P$ wave attenuation in the upper mantle beneath regional network stations. We expect the influence of the lower mantle on $\Delta t_{P}^{*}$ to be small because attenuation in the lower mantle is relatively weak and $P$ waves have similar lower mantle propagation paths for nearby stations (Figure 1). One of the benefits of using the spectral ratio over using the amplitude ratio to infer the variation in $t_{P}^{*}$ is that the shapes of spectra are not as sensitive to other elastic effects such as crustal amplification, azimuthal variation, focusing, and local scattering near the source as they are to $t_{P}^{*}$ while the amplitudes of body waves are severely affected by local focusing [Der et al., 1982].

[14] We restrict our analysis to teleseismic $P$ wave recordings of deep (focal depths $>200 \mathrm{~km}$ ) earthquakes. $P$ signals for deep earthquakes have relatively short durations without significant directivity [Houston and Vidale, 1994]. Moreover, they are not complicated by surface reflections (i.e., $p P$ and $s P$ ) nor attenuated by the uppermost mantle in the source region. For epicentral distances larger than $30^{\circ}$ and smaller than $85^{\circ}, P$ waves turn below the $660 \mathrm{~km}$ discontinuity and above the heterogeneous $\mathrm{D}^{\prime \prime}$ region, where vertical velocity gradients are well understood. However, since teleseismic $P$ waves propagate steeply through the upper mantle, $\Delta t_{P}^{*}$ does not constrain depth variation of attenuation.

[15] We select our recordings from 378 stations (Figure 2). These include Global Seismic Network and GEOSCOPE stations in the U.S. and Canada and regional network stations from the Canadian National Seismic Network (CNSN), the United States National Seismic Network (USNSN), TriNet [Kanamori et al., 1997], the Berkeley Digital Seismic Network (BDSN) [Romanowicz et al., 1993], NARS-Baja [Trampert et al., 2003], and broadband PASSCAL arrays that have been archived at the IRIS Data Management Center. $P$ waves on broadband (10 samples per second) vertical component velocity seismograms are corrected for the instrument response and high-pass filtered with a corner frequency of $120 \mathrm{~s}$ to reduce long-period noise. By visual inspection, we select the highest-quality recordings of $P$ waves with signal-to-noise ratios of at least 20, low-amplitude coda, and impulsive onsets and we determine time windows to ensure that the same features of $P$ waveforms are analyzed. $P$ wave spectra are estimated by multiple-taper spectral analysis [Lees and Park, 1995] and spectral ratios $\ln R$ are measured up to $1 \mathrm{~Hz}$. The use of multiple-tapers produces smoother spectra and, hence, more robust estimates of $\ln R$. However, after experimentation with single and multiple tapers we observe that the spatial distribution of $t_{P}^{*}$ depends little on the choice of the taper.

[16] Figure 3 shows representative examples of spectral ratios and the measurement variability in $\Delta t_{P}^{*}$ for ten deep earthquakes in South America recorded at stations CCM (Cathedral Cave, Missouri) and ANMO (Albuquerque, New Mexico). It demonstrates that, for nearly all earthquakes, the $P$ wave signals at ANMO (which is located in TNA) are depleted in high frequencies compared to the $P$ wave signals recorded at CCM (which is located in SNA). For each waveform pair, the spectral ratio $\ln R$ increases with increasing frequency and, hence, values for $\Delta t_{P}^{*}\left(t_{P}^{*} \mathrm{CCM}^{-}\right.$ $t_{P}^{*}$ ANMO) are negative. This suggests that $P$ waves propagating to ANMO are more attenuated. However, inferred values for $\Delta t_{P}^{*}$ vary between $-0.24 \mathrm{~s}$ and $-1.09 \mathrm{~s}$, more than measurement errors in $\Delta t_{P}^{*}( \pm 0.05-0.37 \mathrm{~s})$. The variable $\Delta t_{P}^{*}$ reflects the complex (nonlinear) character of $\ln R$, especially at frequencies larger than $0.8 \mathrm{~Hz}$, which we attribute to receiver effects. In general, we obtain

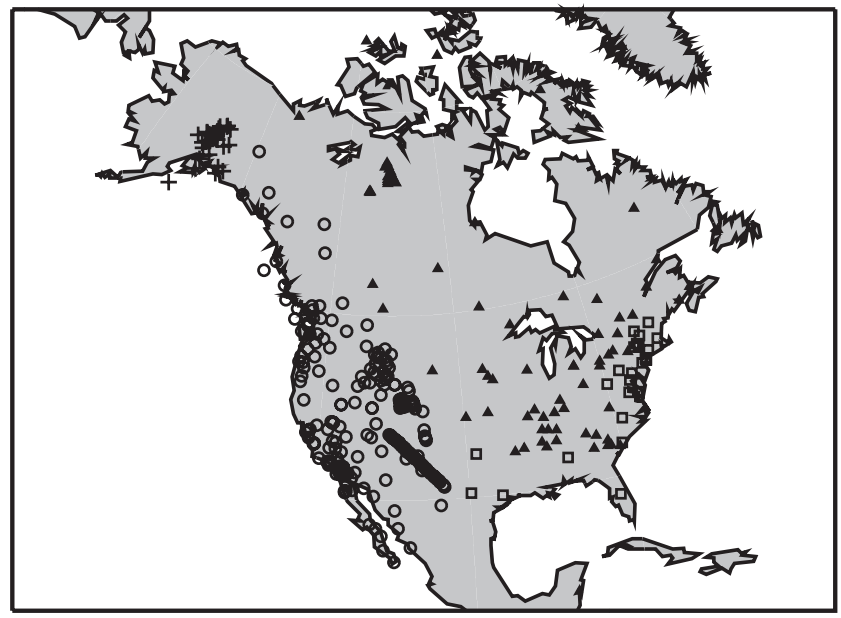

Figure 2. Open circles, closed triangles, open squares, and crosses indicate the locations of the 378 seismic stations used in this study. These stations are located in, respectively, SNA, TNA, the off-platform region, and subduction zone in southern Alaska. 

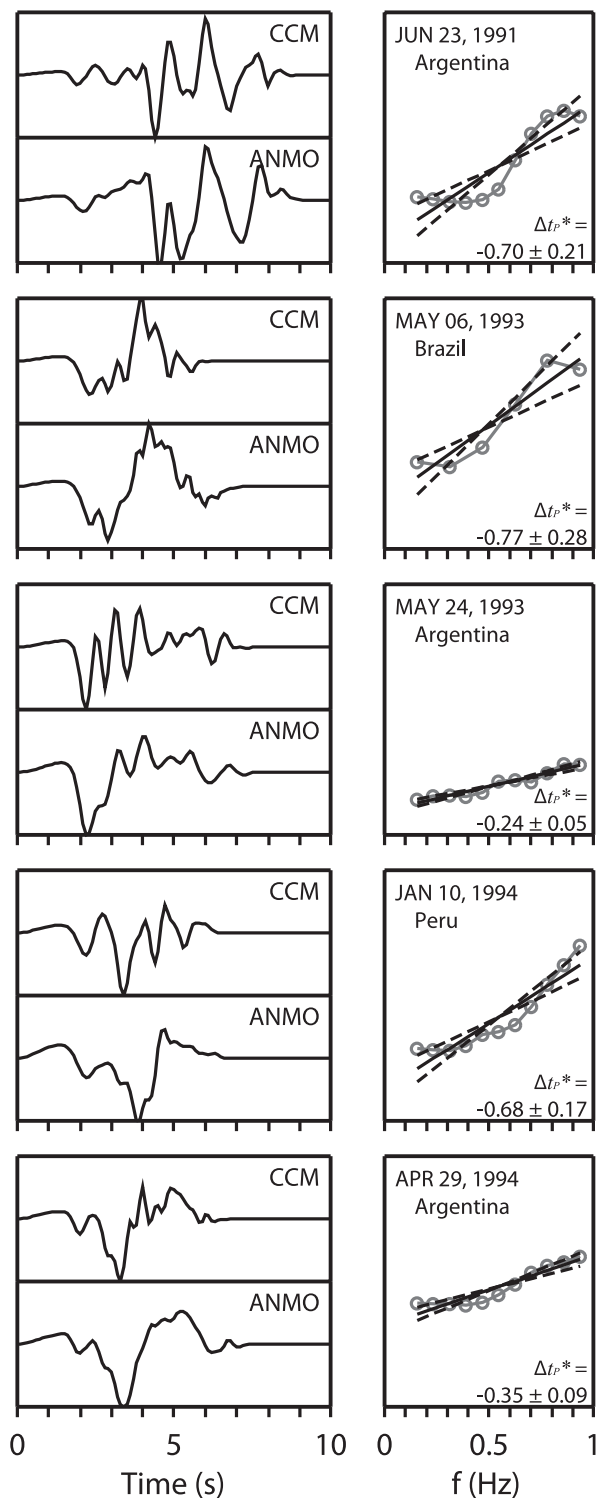
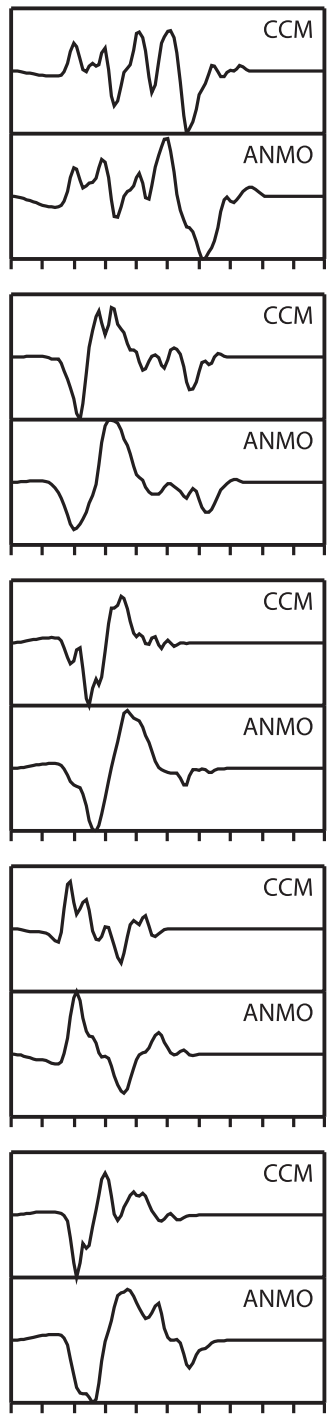

0

Time (s)
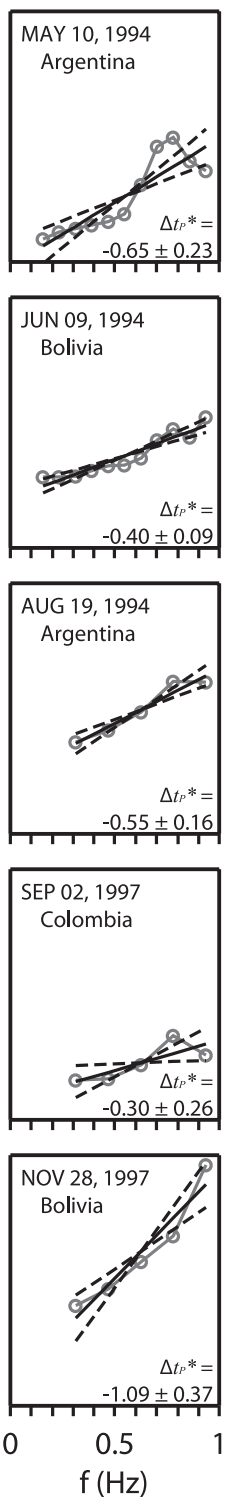

Figure 3. Selected measurements of $\Delta t_{P}^{*}$ between stations CCM (Cathedral Caves, MO) and ANMO (Albuquerque, NM) for ten deep earthquakes in South America. (left) Vertical component velocity waveforms. Trace windows are manually determined such that seismograms for the same event contain the same features of $P$ wave arrivals. (right) Natural logarithm of spectral ratios $\ln R(f)$ (gray lines with circles), best fitting lines to $\ln R$ (black solid lines), and lines with slopes that bracket the $95 \%$ certainty of the slope (black dashed lines). $\Delta t_{P}^{*}$ measurements and their uncertainties are in seconds.

the most accurate measurements of $\Delta t_{P}^{*}$ (i.e., measurements with uncertainties lower than $2 \sigma$ ) for $P$ waves with simple waveforms composed of a single upswing and downswing) and shortest durations. Presumably, these measurements better quantify the integrated effects of intrinsic attenuation on $P$ wave spectra.

[17] We observe significant variability of $\Delta t_{P}^{*}$ for most station pairs (Figure 4). While absolute $\Delta t_{P}^{*}$ values are larger than $0.1 \mathrm{~s}$ for about $75 \%$ of the measurements, the measurement uncertainty peaks at around $0.1 \mathrm{~s}$. Thus, to constrain $\Delta t_{P}^{*}$ we must rely on data redundancy and multiple measurements for earthquakes at different azimuths. Therefore we collect a data set of more than 63,000 spectral ratios using stations for which we have at least two events.

\subsection{Least Squares Inversion}

[18] To estimate $t_{P}^{*}$ for each station, we solve a set of linear equations. First, the measurements of the slopes of the best fitting lines to $\ln R_{i j}$ provide estimates of the $t_{P}^{*}$ difference $\left(\Delta t_{P}^{*}{ }_{k}\right)$ between stations $i$ and $j$ :

$$
w_{k}^{1}\left(t_{P}{ }^{*}{ }_{i}-t_{P}{ }_{j}\right)=w_{k}^{1} \Delta t_{P}{ }_{k} .
$$

Here $w_{k}^{1}$ is a weight factor

$$
w_{k}^{1}=\exp \left[-\left(\varepsilon_{k} / \varepsilon_{0}\right)^{2}\right] \exp \left[-\left(\Delta_{k} / \Delta_{0}\right)^{2}\right],
$$

which includes factors determined by the $2 \sigma$ uncertainty in the $\Delta t_{P}^{*}{ }_{k}$ measurement $\left(\varepsilon_{k}\right)$ and the interstation distance 


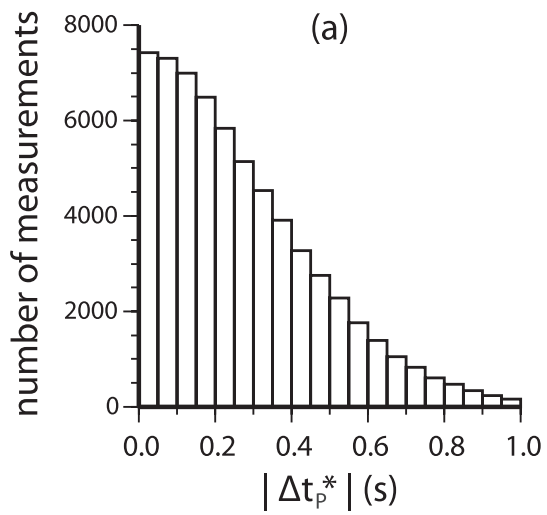

(b)

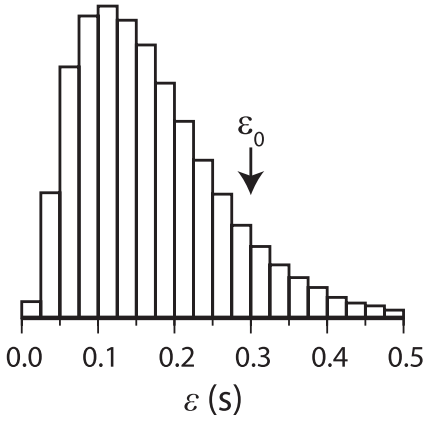

(c)

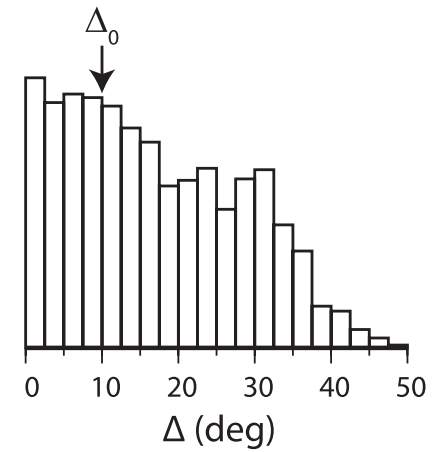

Figure 4. (a) Distribution of $\left|\Delta t_{P}^{*}\right|$. (b) Distribution of $95 \%$ confidence ranges of $\Delta t_{P}^{*}$. Reference value $\varepsilon_{0}$ $=0.3 \mathrm{~s}$ is chosen. (c) Interstation distance distribution of station pairs used in this study. Reference value $\Delta_{0}=10^{\circ}$ is chosen.

$\left(\Delta_{k}\right)$. The first factor in (6) reduces the weight of measurements $\Delta t_{P}^{*}$ with the highest $2 \sigma$ uncertainty. The second factor reduces the weight of measurements of $\Delta t_{P}^{*}$ for stations that are separated most and for which the effects of variable attenuation in the lower mantle may be greatest. We choose reference values $\varepsilon_{0}=0.3 \mathrm{~s}$ (Figure $4 \mathrm{~b}$ ) and $\Delta_{0}=$ $10^{\circ}$ (Figure 4c) so that measurements with uncertainties larger than $0.3 \mathrm{~s}$ and measurements for which the station separations are more than $10^{\circ}$ have weights that are reduced by at least $1 / e$. The inversion results change little when $\varepsilon_{0}$ is larger than $0.3 \mathrm{~s}$ and when $\Delta_{0}$ is larger than $10^{\circ}$ because $\Delta t_{P}^{*}{ }_{k}$ for the same pair of stations have, in general, the same signs.

[19] Second, we impose that the average value of $t_{P}^{*}$ is zero:

$$
\sum_{n=1}^{378} t_{P n}^{*}=0
$$

since the differential $t_{P}^{*}$ measurements do not constrain the absolute value of $t_{P}^{*}$. Thus, in our maps, only the variation in $t_{P}^{*}$ is estimated.

[20] Third, we impose smoothness constraints by penalizing $t_{P}^{*}$ differences for closely located stations:

$$
w_{k}^{2}\left(t_{P}{ }_{i}-t_{P}{ }_{j}\right)=0 .
$$

The factor

$$
w_{k}^{2}=\exp \left[-\left(\Delta_{k} / \Delta_{R}\right)^{2}\right]
$$

is largest when the angular distance $\Delta_{k}$ between stations $i$ and $j$ is smallest. In section 4.1, we experiment with values for the reference distance $\Delta_{R}$ by examining data misfit reduction and model norm.

[21] Equations (5), (7), and (8) can be written in matrix form as

$$
\mathbf{G m}=\mathbf{d},
$$

where $\mathbf{m}$ is the model vector composed of $t_{P}^{*}$ for 378 stations:

$$
\mathbf{m}=\left(t_{P}{ }_{1}, t_{P}{ }_{2}, t_{P} *_{3}, \cdots, t_{P}{ }_{378}\right) \text {. }
$$

We solve (10) by least squares inversion.

\section{4. $t_{P}^{*}$ Structure}

\subsection{Effect of Smoothing}

[22] In order to determine the effects of the smoothing parameter $\Delta_{R}$, we determine model norm $\left(\mathbf{m} / \mathbf{m}_{0}\right)^{2}$, misfit reduction $1-((\mathbf{G m}-\mathbf{d}) / \mathbf{d})^{2}$ (Figure 5), and $t_{P}^{*}$ as a function of $\Delta_{R}$ (Figure 6). Figure 5 illustrates the trade-off between model norm and misfit reduction. For low values of $\Delta_{R}$, the model norm is high $\left(\left|t_{P}^{*}\right|\right.$ values are relatively large) and misfit reduction is highest (i.e., data fit is best). For increasing $\Delta_{R}$, both model norm and misfit reduction decrease and the $t_{P}^{*}$ contrast between TNA and SNA emerges as the predominant signal. We choose $\Delta_{R}=3^{\circ}$ as the preferred smoothness value as we suppress the strong variations in $t_{P}^{*}$ for nearby stations within the western US while maintaining coherent variations in $t_{P}^{*}$ within TNA and SNA (e.g., relatively high $t_{P}^{*}$ around the Appalachian) for which we may seek geophysical explanations. However,

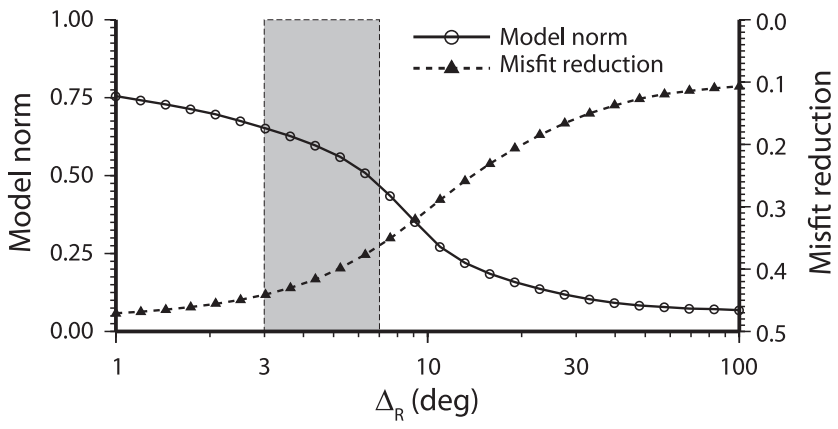

Figure 5. Trade-off curves for the model norm (solid line with circles) and the misfit reduction (dashed line with triangles) as a function of $\Delta_{R}$. Circles and triangles are calculated data points of the model norm and the misfit reduction, respectively. Values of $\Delta_{R}$ in the shaded region $\left(\Delta_{R}=3-7^{\circ}\right)$ are preferred values. 


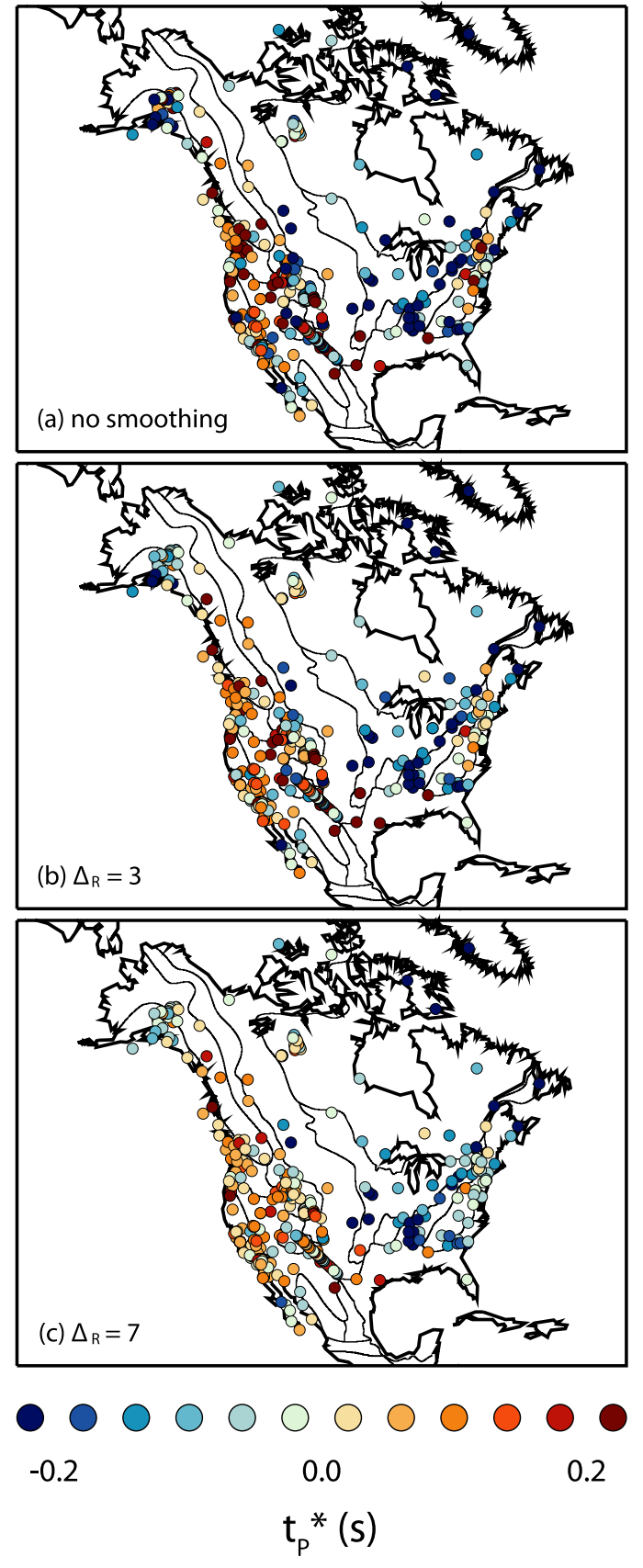

Figure 6. Maps of $t_{P}^{*}$ resolved with varying smoothing parameters $\Delta_{R}$. (a) No smoothing is imposed. (b) $\Delta_{R}=3^{\circ}$. (c) $\Delta_{R}=7^{\circ}$.

an acceptable misfit reduction is obtained for $\Delta_{R}$ as high as $7^{\circ}$.

\subsection{Variation in $t_{P}^{*}$}

[23] Our preferred map of $t_{P}^{*}$ variation (Figure 6b) shows both a simple regional trend and small-scale variations. The characteristic dichotomy of SNA and TNA is reflected in predominantly low $t_{P}^{*}$ values for stations in SNA, including the Canadian Shield, Midcontinent, Grenville Province, and most of the Great Plains, while high values of $t_{P}^{*}$ are observed in TNA. We illustrate the regional variation in $t_{P}^{*}$ further by dividing the stations into four groups for distinct terrains in North America (Figure 7). The main variations can be associated with regional tectonic settings. Low $t_{P}^{*}$ values for stations in SNA and high $t_{P}^{*}$ values for stations in TNA are shown clearly in Figures $7 \mathrm{a}$ and $7 \mathrm{~b}$, respectively. On average, the difference in $t_{P}^{*}$ between SNA and TNA is $0.23 \mathrm{~s}$ when no smoothing is applied and is $0.16 \mathrm{~s}$ if $\Delta_{R}$ is increased to $7^{\circ}$.

[24] Smaller-scale $(<1000 \mathrm{~km})$ variations of $t_{P}^{*}$ are embedded within this large-scale trend and they are as strong as the bimodal TNA/SNA variation. We can readily recognize these variations in individual spectral ratio measurements. Compared to the predominant low $t_{P}^{*}$ values at stations in SNA (Figure 7a), relatively high values for $t_{P}^{*}$ are resolved for stations around the Appalachians and Gulf coast off the stable platform (Figure 7c), where mantle shear and $P$ velocities are also relatively low. Low $t_{P}^{*}$ are found under southern Alaska and around Baja California (Figure 7d), probably associated with ongoing subduction in Alaska, while $t_{P}^{*}$ are relatively high in the rest of western North America (Figure 7b).

\section{Comparison With Other Studies}

[25] The first-order pattern of high $t_{P}^{*}$ in TNA and low $t_{P}^{*}$ in SNA is consistent with previous studies of shortperiod amplitude anomalies [Cleary, 1967; Booth et al., 1974; Der et al., 1982; Butler, 1984], spectral ratio variations [Solomon and Toksöz, 1970; Der and McElfresh, 1976, 1977; Der et al., 1982], Lg coda waves [Baqer and Mitchell, 1998], and regional Rayleigh waves [Mitchell, 1975]. The contrast in $t_{P}^{*}$ of $0.2 \mathrm{~s}$ between SNA and TNA is consistent with that inferred by Der et al. [1982] who studied $P$ wave spectra at frequencies up to $4 \mathrm{~Hz}$. From $P$ wave amplitudes, values of $\Delta t_{P}^{*}$ larger than $0.4 \mathrm{~s}$ have been reported by Solomon and Toksöz [1970] and Lay and Helmberger [1981]. In contrast, the recent study by Lawrence et al. [2006] suggests that there is no significant large-scale variation in $t_{P}^{*}$ across North America. This observation is clearly inconsistent with our study. We speculate that the discrepancy is due to the fact that $t_{P}^{*}$ variation may be difficult to detect in spectral ratios within the low frequency band ( $<0.1 \mathrm{~Hz}$ ) that Lawrence et al. [2006] use.

[26] Lay and Wallace [1988] resolve strong $Q_{S}$ variations within western North America using $S c S$ multiples. Averaged over the upper $400 \mathrm{~km}$ of the mantle, they suggest that $Q_{S}=25$ beneath the Basin and Range and $Q_{S} \geq 1000$ beneath the Pacific Northwest. This contrast would imply $t_{P}^{*}$ variations of about $0.4 \mathrm{~s}$, a factor of 2 higher than what we observe. This discrepancy that may partially be due to a strong $\mathrm{D}^{\prime \prime}$ influence on $S c S$ attenuation measurements. Strong (frequency-dependent) wave attenuation beneath the Basin and Range is also inferred from regional $L g$ wave [Chavez and Priestley, 1986; Benz et al., 1997] and Rayleigh wave studies [Hwang and Mitchell, 1987].

[27] The main patterns in our $t_{P}^{*}$ maps, including those at regional scale, are similar to those found in surface heat flow (Figure 8d). The low heat flow in southeastern U.S. does not correlate with the high $t_{P}^{*}$ anomaly in this region. However, Artemieva et al. [2000] did infer higher lithospheric temperatures for the southeastern U.S. than in the SNA interior by reevaluation of heat flow data that takes 
(a) SNA

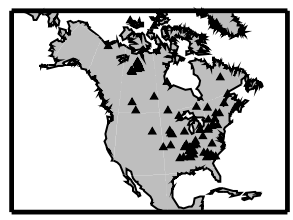

no smoothing

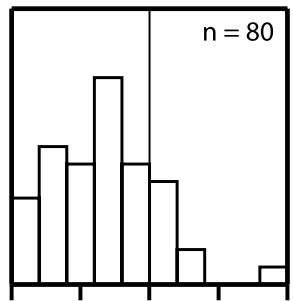

$\Delta_{\mathrm{R}}=3^{\circ}$

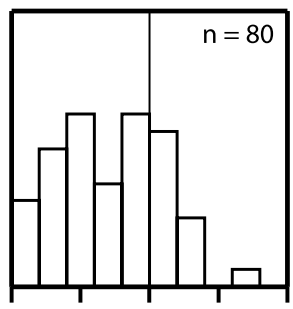

$\Delta_{\mathrm{R}}=7^{\circ}$

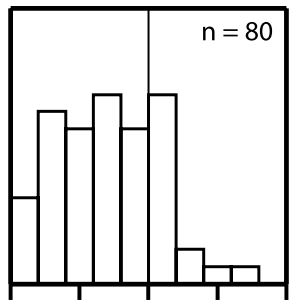

Model Q

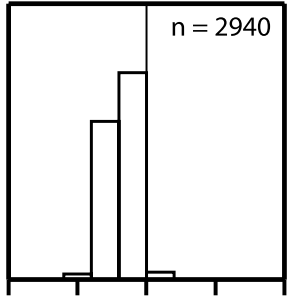

Model T

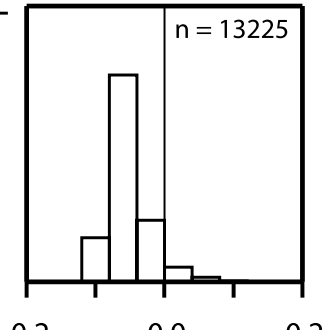

(b) TNA
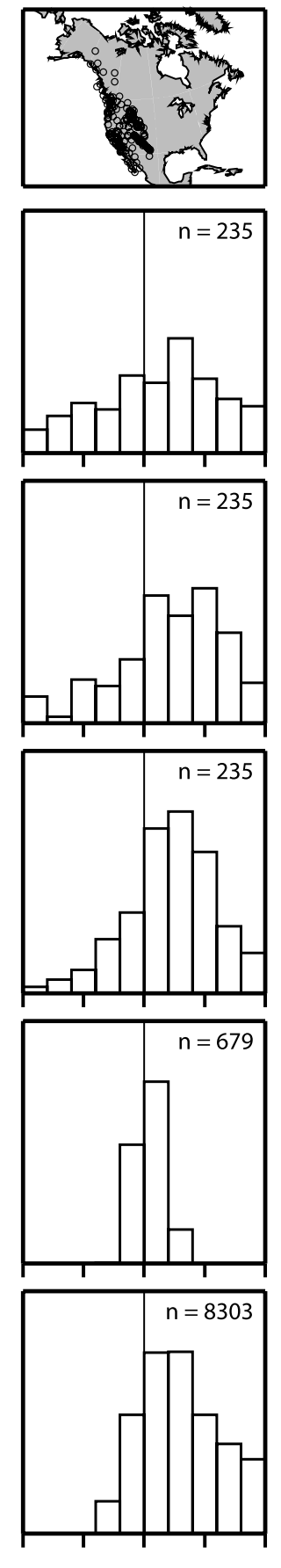

(c) Off-platform
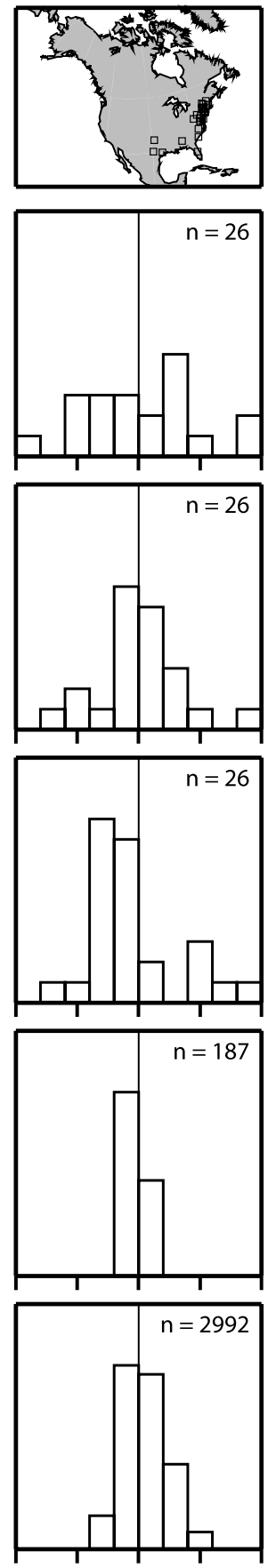

$\begin{array}{lll}-0.2 & 0.0 & 0.2\end{array}$ (d) S. Alaska
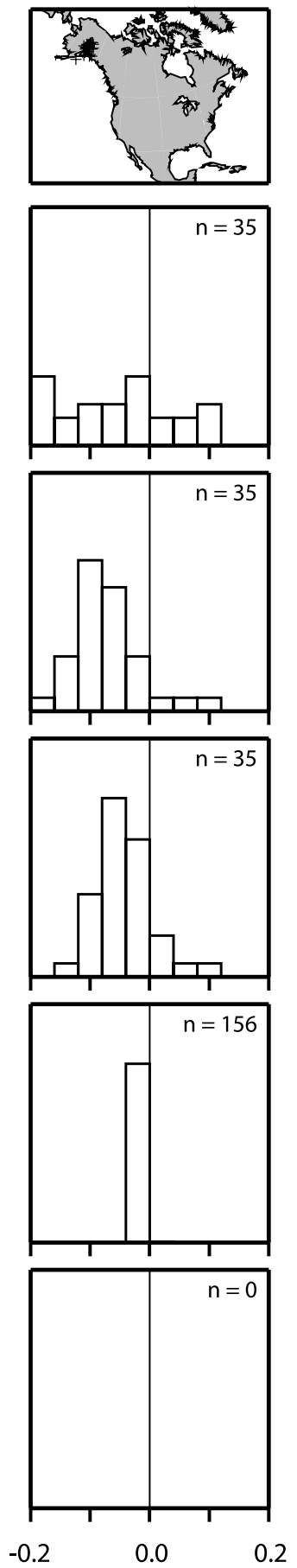

$t_{p}^{*}(s)$

Figure 7. Distributions of $t_{P}^{*}$ (this article), $t_{O}^{*}$ (from model Q: global surface $Q$ tomography [Dalton et al., 2008]), and $t_{T}^{*}$ (from model $\mathrm{T}$ : regional $Q_{S}$ from temperature estimates [Goes and van der Lee, 2002]) for stations in (a) SNA, (b) TNA, (c) off-platform region, and (d) subduction zone in southern Alaska. $\mathrm{n}$ represents the total number of data points used to produce each distribution diagrams.

into account the thermal properties of the region's crust. The similarity of surface heat flow and $t_{P}^{*}$ implies that thermal structure affects intrinsic attenuation to a significant extent at shallow mantle depth.
[28] Next, we make a more detailed comparison with two recent attenuation models based on surface wave analyses. We refer to these models as models Q and T. Model Q is the global model QRFSI12 by Dalton et al. [2008]. Model T is 

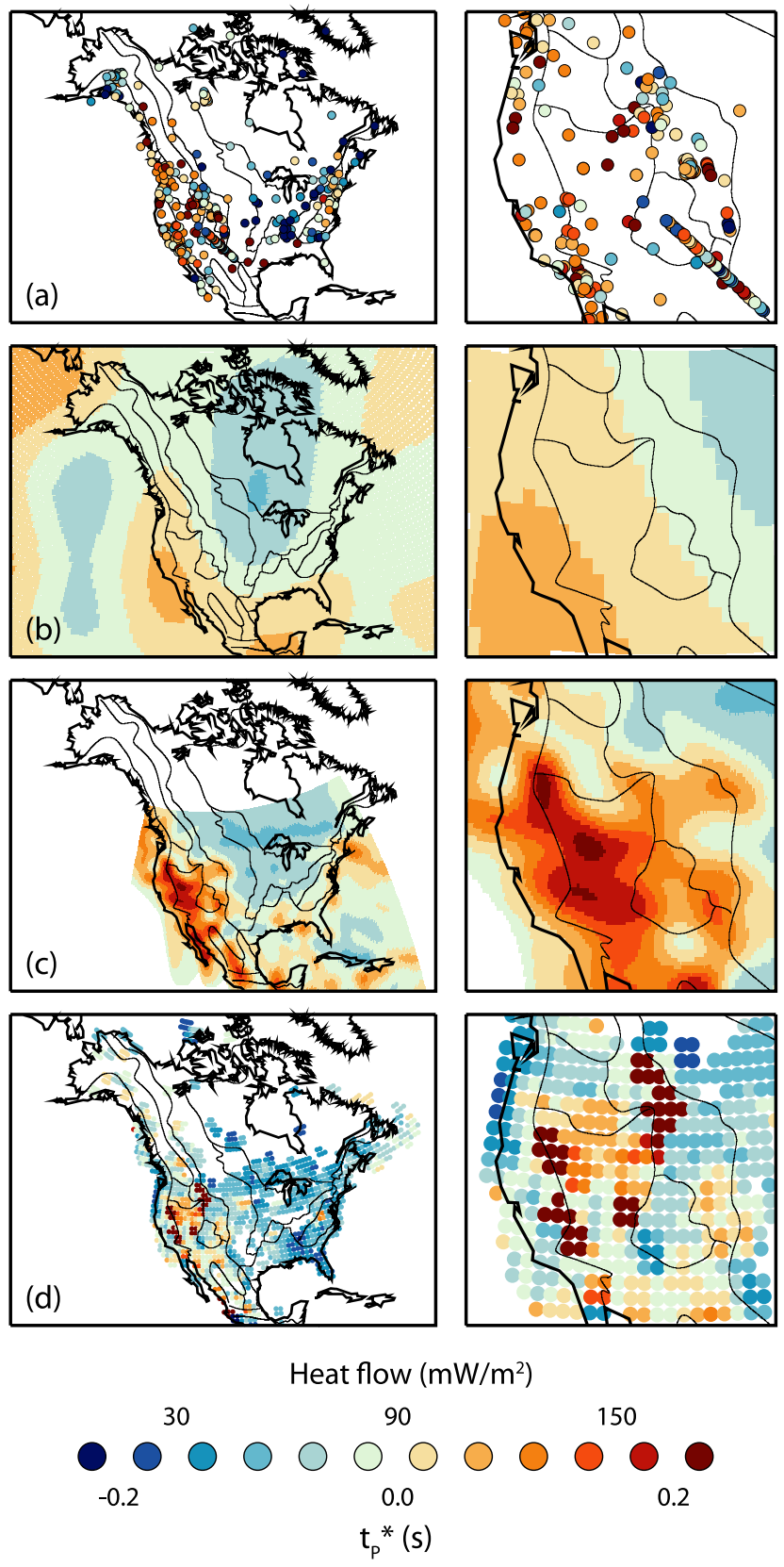

Figure 8. (a) Variation of $t_{P}^{*}$ for $\Delta_{R}=3^{\circ}$. (b) Variation of $t_{O}^{*}$ (from model Q: global surface $Q$ tomography [Dalton et al., 2008]). (c) Variation of $t_{T}^{*}$ (from model T: regional $Q_{S}$ from temperature estimates [Goes and van der Lee, 2002]). (d) Variation of cap-averaged heat flow data from Pollack et al. [1993]. (left) Variations in North America. (right) Variations within TNA.

derived from the regional $S$ velocity model for NA00 [Van der Lee, 2002] for North America by converting shear velocity to temperature [Goes and van der Lee, 2002]. The conversion accounts for both elastic and anelastic sensitivity of the seismic waves to temperature and as a result yields an accompanying anelasticity model.

[29] We denote predicted values of $t_{P}^{*}$ for model $\mathrm{Q}$ as $t_{Q}^{*}$, using the subscript " $Q$ " to emphasize that $t_{P}^{*}$ values are computed using a $Q_{S}$ model for the mantle. The predicted $t_{P}^{*}$ for model $\mathrm{T}$ are denoted as $t_{T}^{*}$, using a subscript " $T$ " to indicate that we employ a temperature conversion to infer $t_{P}^{*}$ from a tomographically derived shear velocity model.

[30] The comparison with model Q (and $t_{Q}^{*}$ ) will help us gain insight into the compatibility of attenuation inferred from $P$ wave spectra and long-period surface wave amplitudes. The comparison with model $\mathrm{T}$ (and $t_{T}^{*}$ ) will enable us to evaluate the similarity of regional-scale variations in $t_{P}^{*}$ and shear velocity, and whether interpreting North American shear wave structure as being dominantly thermally controlled is compatible with independent constraints on attenuation. Figure 8 compares the $t_{P}^{*}$ map from Figure $6 \mathrm{~b}$ to predicted values of $t_{P}^{*}$ across North America for models Q $\left(t_{Q}^{*}\right)$ and $\mathrm{T}\left(t_{T}^{*}\right)$. The distribution of $t_{P}^{*}, t_{Q}^{*}$, and $t_{T}^{*}$ is shown in Figure 7.

\subsection{Model Q: Global Surface Wave $Q$ Tomography \\ 5.1.1. Model Q Background}

[31] Model QRFSI12 [Dalton et al., 2008] is the most recent global $Q_{S}$ model based on surface wave amplitudes. QRFSI12 has been derived using more than 30,000 Rayleigh wave amplitudes measurements. These amplitudes have been corrected for the effects of surface wave focusing and inverted simultaneously for three-dimensional attenuation $\left(Q_{S}\right)$ and correction factors for the source and receiver. Lateral variations of $Q_{S}$ in QRFSI12 are parameterized using spherical harmonics up to degree 12 . The shortest wavelength variations are therefore about $3000 \mathrm{~km}$ which limits a comparison to continental-scale variations. We convert $Q_{S}$ from QRFSI12 to $Q_{P}$ using $Q_{P}=3 /{ }_{4}\left(V_{P} / V_{S}\right)^{2}$ $Q_{S}$, assuming that attenuation in bulk is negligible, and we adopt $V_{P}$ and $V_{S}$ velocities from the PREM model [Dziewonski and Anderson, 1981].

[32] We calculate $t_{O}^{*}$ by integrating along a $P$ wave raypath for an epicentral distance of $70^{\circ}$ through the upper $370 \mathrm{~km}$ of the mantle using (2). We assume that $Q_{P}$ varies only with depth, because lateral variations in $Q_{P}$ are smooth and teleseismic $P$ wave propagate steeply through the uppermost mantle.

\subsubsection{Comparison Between $t_{O}^{*}$ and $t_{P}^{*}$}

[33] The $t_{Q}^{*}$ variation (Figure $8 \mathrm{~b}$ ) is, as expected, smooth given the relatively coarse lateral parameterization of QRFSI12. The contrast between SNA and TNA, a regional variation that is at the limit of global resolution in QRFSI12, is well reproduced in $t_{Q}^{*}$ and correlates well with $t_{P}^{*}$, with a correlation coefficient of 0.30 , on a point by point basis. The correlation coefficient increases to 0.38 and to 0.40 for $\Delta_{R}=3^{\circ}$ and $\Delta_{R}=7^{\circ}$, respectively.

[34] The peak-to-peak variation in $t_{O}^{*}$ is a factor of 6 smaller than in the preferred $t_{P}^{*}\left(\Delta_{R}=3^{\circ}\right)$. Even for stronger damped distributions of $t_{P}^{*}\left(\Delta_{R}=12^{\circ}\right)$ for which the lateral resolutions of $t_{O}^{*}$ and $t_{P}^{*}$ are roughly equal, the amplitude in $t_{Q}^{*}$ is still a factor of 2.2 smaller. We attribute the amplitude mismatch to the relatively long wavelength parameterization and strong damping used in constructing QRFSI12.

\subsection{Model T: Regional $Q_{S}$ From Temperature Estimates}

\subsubsection{Model $T$ Background}

[35] Model $\mathrm{T}$ is a regional $Q_{S}$ model derived from a purely thermal interpretation [Goes and van der Lee, 2002] 
of shear velocity model NA00 [Van der Lee, 2002], assuming a constant pyrolitic composition. Taking into account that temperature variations affect both elastic and anelastic seismic structure, the conversion yields all elastic constants, density, and $Q_{S}$ and $Q_{P}$ for the temperature structure inferred from $V_{S}$. Because of the exponential dependence of anelasticity on temperature, even strong low-velocity anomalies generally translate into subsolidus temperatures that are compatible with temperatures derived from an independent $V_{P}$ model and surface heat flow [Goes and van der Lee, 2002].

[36] The temperature-velocity calculations were slightly updated from those used by Goes and van der Lee [2002] to make them more suitable for depths between $200 \mathrm{~km}$ and $400 \mathrm{~km}$. We employ a finite, rather than infinite, strain equation of state that includes the effect of phase transformations within the pyrolitic mantle, as in the study by Goes et al. [2005]. We use a temperature and depthdependent anelasticity formulation: $Q_{S}(T, P)=Q_{0}$ $\exp \left[g T_{\mathrm{m}}(P) / T\right]$, where $Q_{0}$ is set to $0.1 \cdot \omega^{0.15}, \omega$ is frequency, $g$ is a constant scaling factor set to $40, T_{\mathrm{m}}$ is the peridotite solidus, and $T$ is absolute temperature. This is an empirical approximation of the common Arrhenius-type expression $Q_{S}(T, P)=Q_{0} \cdot \exp \left[\left(E^{*}+P V^{*}\right) / T\right]$, where $E^{*}$ and $V^{*}$ are activation energy and volume, respectively [Karato and Spetzler, 1990]. Using the scaled homologous temperature, $T / T_{\mathrm{m}}$, is a way of parameterizing the plausible decrease of $V^{*}$ with depth [e.g., Yamazaki and Karato, 2001]. A constant $V^{*}$ yields negative upper mantle $Q_{S}$ depth gradients below the asthenosphere. At depths down to about $200 \mathrm{~km}$, the model is similar to the average $Q$ model $Q_{1}$ (with $E^{*}=500 \mathrm{~kJ} / \mathrm{mole}$ and $V^{*}=20 \mathrm{~m}^{3} /$ mole) used by Goes and van der Lee [2002]. Bulk $Q$ is kept constant at a value of 1000. The updated procedure gives temperatures that are, within a few tens of degrees, i.e., within the uncertainties due to uncertainties in the mineral parameters, identical to those from Goes and van der Lee [2002].

\subsubsection{Comparison Between $t_{T}^{*}$ and $t_{P}^{*}$}

[37] Because of the relatively high lateral resolution of NA00, $t_{T}^{*}$ (Figure $8 \mathrm{c}$ ) shows more variability than $t_{Q}^{*}$. In addition to the bimodal SNA-TNA variation, $t_{T}^{*}$ includes high values below the Appalachians and Gulf Coast, and lower values under the Colorado Plateau that are also observed in $t_{P}^{*}$. This indicates that not only the continentalscale pattern but some of the $t_{P}^{*}$ features that are coherent on a $2^{\circ}$ scale may be the result of intrinsic attenuation. However, the point-by-point correlation coefficient between $t_{P}^{*}$ and $t_{T}^{*}$ of 0.23 is relatively low and thus shows that many of the high and low shear velocity anomalies do not correspond to high and low $Q$ anomalies.

[38] The amplitude variation in $t_{T}^{*}$ is in good agreement with the variation of $t_{P}^{*}$. The similar amplitudes of $t_{P}^{*}$ and $t_{T}^{*}$ indicate that the assumptions underlying the conversion of shear velocity variation to $Q_{P}$ are reasonable. $Q_{P}$ in model $\mathrm{T}$ varies over at least 6 orders of magnitude from essentially infinite under the North American shield, to minimum values of $40\left(Q_{S}\right.$ of 17) around $70 \mathrm{~km}$ depth below the western U.S. Higher $Q_{P}$ (and hence higher $Q_{S}$ ) values within the western US would reduce $t_{T}^{*}$ values which already somewhat underestimate $t_{P}^{*}$.

[39] Thus $Q$ values below the western US appear to be very low. Similarly low $Q$ values have been invoked below mid-ocean ridges in models that reconcile oceanic lithospheric cooling models and sub-oceanic surface wave velocities [Faul and Jackson, 2005; Priestley and McKenzie, 2006]. These models self-consistently generate a low-velocity zone without requiring significant amounts of partial melt. However, surface wave analyses from data of the East Pacific Rise RIDGE experiment find minimum $Q s$ values no lower than 80 below the ridge [Yang et al., 2007]. To reconcile very low seismic velocities and moderately low $Q s$ values, the authors propose the presence of melt which does not attenuate substantially in the seismic frequency band but lowers seismic velocities due to elastic effects.

[40] We find that for the western U.S., where mantle seismic velocities are, over $1000 \mathrm{~km}$ scales, as low as at mid-ocean ridges, measured $t_{P}^{*}$ are matched well with very low $Q$ values. Such low $Q$ values can be purely thermal (as was assumed in their derivation), but may also be partially controlled by water content. Dixon et al. [2004] has proposed that the western U.S. subcrustal mantle is both hot and wet. As the seismic effect of water at shallow mantle depths is most likely predominantly anelastic, water affects seismic velocities and $Q$ simultaneously, and cannot be distinguished from purely thermal effects without independent temperature data [Karato, 1993]. The relatively large scatter in surface heat flow data and uncertainties in their extrapolation to temperature at depth does not preclude that part of the seismic structure is controlled by variations in water content [Dixon et al., 2004]. In any case, the variable seismic velocities in the North American upper mantle seismic structure are linked to strong attenuation variations. This strongly suggests that these seismic signatures are caused by variations in temperature and water content, and probably not by composition and melt.

\section{Conclusions}

[41] We have inverted about 63,000 measurements of the spectral ratio of broadband (from one over signal length to $1 \mathrm{~Hz}) P$ waves generated by deep (focal depths $>200 \mathrm{~km}$ ) earthquakes and recorded at 378 stations in North America. This large data set provides better constrained and more densely distributed information on uppermost mantle $P$ wave attenuation below the continent than has been previously available.

[42] The pattern of $t_{P}^{*}$ shows a systematic contrast between tectonic North America (TNA) and stable North America (SNA). $t_{P}^{*}$ is relatively high in TNA and low in SNA consistent with high and low $P$ wave attenuation in the upper mantle beneath TNA and SNA, respectively. This general pattern has been observed before in the US; improved data coverage in Canada confirms that the continental-scale $t_{P}^{*}$ pattern matches very well with the age of geological terrains and the seismic, heat flow, gravity, and magnetic variations across North America. The variation of $t_{P}^{*}$ of $0.2 \mathrm{~s}$ between TNA and SNA is compatible with previous estimates.

[43] We resolve regional variations in $t_{P}^{*}$ which correlate with tectonics: relatively low $t_{P}^{*}$ is associated with currently active subduction below Alaska. Relatively high $t_{P}^{*}$ is found in SNA below the Appalachians and the Gulf Coast.

[44] The consistency between patterns on the scale of around $200-500 \mathrm{~km}$ and tectonics suggests that the ob- 
served variations in $t_{P}^{*}$ are predominantly due to intrinsic attenuation. The similar patterns in our $t_{P}^{*}$ and predicted values for global attenuation model QRFSI12 [Dalton et al., 2008] based on Rayleigh waves, which samples the upper mantle in a fundamentally different manner than teleseismic $P$ waves, confirm this further. Compatibility with the $t_{P}^{*}$ computed for attenuation estimated via a thermal interpretation of shear wave velocity anomalies in regional $V s$ model NA00, illustrates that variations in seismic velocity are predominantly due to physical effects with a strong attenuation signature, most likely temperature or a combination of temperature and water content.

[45] Acknowledgments. Data have been provided by the IRIS/DMC, the GEOSCOPE Data Center, the Geological Survey of Canada, the Southern California Seismic Network (SCSN) Data Center operated by Caltech and USGS, and the Northern California Earthquake Data Center (NCEDC), a joint project of the University of California Berkeley Seismological Laboratory (BSL) and the USGS. Figures are produced by GMT (Generic Mapping Tools) software. We thank Colleen Dalton for providing us with her $Q$ model and for giving advice on model interpretation. We thank Jonathan Lees for providing us with the MTM (Multi-Taper Spectral Analysis Methods) software. Constructive comments by two anonymous reviewers and the Associate Editor helped us improve the article. This research has been supported by NSF grant EAR-0609763.

\section{References}

Artemieva, I. M., W. D. Mooney, and N. H. Sleep (2000), Plate motions and the destruction of lithospheric keels, Eos Trans. AGU, 81, 1177.

Baqer, S., and B. J. Mitchell (1998), Regional variation of Lg coda $Q$ in the continental United States and its relation to crustal structure and evolution, Pure Appl. Geophys., 153, 613-638.

Benz, H. M., A. D. Frankel, and D. M. Boore (1997), Regional Lg attenuation for the continental United States, Bull. Seismol. Soc. Am., 87, 606619.

Bhattacharyya, J., G. Masters, and P. M. Shearer (1996), Global lateral variations of shear wave attenuation in the upper mantle, J. Geophys. Res., 101, 22,273-22,289.

Billien, M., J.-J. Leveque, and J. Trampert (2000), Global maps of Rayleigh wave attenuation for periods between 40 and 150 seconds, Geophys. Res. Lett., 27, 3619-3622.

Booth, D. C., P. D. Marshall, and J. B. Young (1974), Long and short period P-wave amplitudes from earthquakes in the range 0 degrees114 degrees, Geophys. J. R. Astron. Soc., 39, 523-537.

Burchfiel, B. C., D. S. Cowan, and G. A. Davis (1992), Tectonic overview of the Cordilleran orogen in the western United States, in The Geology of North America, vol. G-3, The Cordilleran Orogen: Conterminous U.S., edited by B. C. Burchfiel, P. W. Lipman, and M. L. Zoback, pp. 407479, Geol. Soc. of Am., Boulder, Colo.

Butler, R. (1984), Azimuth, energy, $Q$, and temperature: Variations on P wave amplitudes in the United States, Rev. Geophys., 22, 1-36.

Butler, R., and L. Ruff (1980), Teleseismic short-period amplitudes; source and receiver variations, Bull. Seismol. Soc. Am., 70, 831-850.

Chavez, D. E., and K. F. Priestley (1986), Measurement of frequency dependent $\mathrm{Lg}$ attenuation in the Great Basin, Geophys. Res. Lett., 13, $551-554$

Cleary, J. (1967), Analysis of the amplitudes of short-period P waves recorded by long range seismic measurements stations in the distance range 30 degrees to 102 degrees, J. Geophys. Res., 72, 4705-4712.

Cormier, V. F. (1982), The effect of attenuation on seismic body waves, Bull. Seismol. Soc. Am., 72, Part B, S143-S173.

Dallmeyer, R. D., J. E. Wright, D. T. Secor Jr., and A. W. Snoke (1986), Character of the Alleghanian Orogeny in the Southern Appalachians: Part II. Geochronological constraints on the tectonothermal evolution of the eastern Piedmont in South Carolina, Geol. Soc. Am. Bull., 97, $1329-1344$

Dalton, C. A., and G. Ekström (2006), Global models of surface wave attenuation, J. Geophys. Res., 111, B05317, doi:10.1029/2005JB003997.

Dalton, C. A., G. Ekström, and A. M. Dziewoński (2008), The global attenuation structure of the upper mantle, J. Geophys. Res., 113, B09303, doi:10.1029/2007JB005429.

Deen, T. J., W. L. Griffin, G. Begg, S. Y. O'Reilly, L. M. Natapov, and J. Hronsky (2006), Thermal and compositional structure of the subcontinental lithospheric mantle: Derivation from shear wave seismic tomography, Geochem. Geophys. Geosyst., 7, Q07003, doi:10.1029/ 2005GC001120.

Der, Z. A., and T. W. McElfresh (1976), Short-period P-wave attenuation along various paths in North America as determined from P-wave spectra of the SALMON nuclear explosion, Bull. Seismol. Soc. Am., 66, 16091622 .

Der, Z. A., and T. W. McElfresh (1977), The relationship between anelastic attenuation and regional amplitude anomalies of short-period $\mathrm{P}$ waves in North America, Bull. Seismol. Soc. Am., 67, 1303-1317.

Der, Z. A., T. W. McElfresh, and A. O'Donnell (1982), An investigation of the regional variations and frequency dependence of anelastic attenuation in the mantle under the United-States in the $0.5-4 \mathrm{~Hz}$ band, Geophys. J. R. Astron. Soc., 69, 67-99.

Dixon, J. E., T. H. Dixon, D. R. Bell, and R. Malservisi (2004), Lateral variation in upper mantle viscosity; role of water, Earth Planet. Sci. Lett., 222, 451-467.

Durek, J. J., and G. Ekström (1996), A radial model of anelasticity consistent with long-period surface-wave attenuation, Bull. Seismol. Soc. Am., 86, 144-158.

Dziewonski, A. M., and D. L. Anderson (1981), Preliminary reference Earth model, Phys. Earth Planet. Inter., 25, 297-356.

Faul, U. H., and I. Jackson (2005), The seismological signature of temperature and grain size variations in the upper mantle, Earth Planet. Sci. Lett., $234,119-134$.

Godey, S., F. Deschamps, J. Trampert, and R. Snieder (2004), Thermal and compositional anomalies beneath the North American continent, J. Geophys. Res., 109, B01308, doi:10.1029/2002JB002263.

Goes, S., and S. van der Lee (2002), Thermal structure of the North American uppermost mantle inferred from seismic tomography, J. Geophys. Res., 107(B3), 2050, doi:10.1029/2000JB000049.

Goes, S., R. Govers, and P. Vacher (2000), Shallow mantle temperatures under Europe from P and S wave tomography, J. Geophys. Res., 105, $11,153-11,169$

Goes, S., F. J. Simons, and K. Yoshizawa (2005), Seismic constraints on temperature of the Australian uppermost mantle, Earth Planet. Sci. Lett. 236, 227-237.

Grand, S. P., and D. V. Helmberger (1984), Upper mantle shear structure of North America, Geophys. J. R. Astron. Soc., 76, 399-438.

Hammond, W. C., and E. D. Humphreys (2000), Upper mantle seismic wave attenuation: Effects of realistic partial melt distribution, J. Geophys. Res., 105, 10,987-10,999.

Houston, H., and J. E. Vidale (1994), The temporal distribution of seismic radiation during deep earthquake rupture, Science, 265, 771-774.

Humphreys, E. D., and D. D. Coblentz (2007), North American dynamics and western U.S. tectonics, Rev. Geophys., 45, RG3001, doi:10.1029/ 2005RG000181.

Hwang, H.-J., and B. J. Mitchell (1987), Shear velocities, $Q$ (sub beta), and the frequency dependence of $Q$ (sub beta) in stable and tectonically active regions from surface wave observations, Geophys. J. R. Astron. Soc., 90 , $575-613$.

Jackson, I., J. D. Fitz Gerald, U. H. Faul, and B. H. Tan (2002), Grain-sizesensitive seismic wave attenuation in polycrystalline olivine, J. Geophys. Res., 107(B12), 2360, doi:10.1029/2001JB001225.

Kanamori, H., and D. L. Anderson (1977), Importance of physical dispersion in surface wave and free oscillation problems: Review, Rev. Geophys., 15, 105-112.

Kanamori, H., E. Hauksson, and T. Heaton (1997), Real-time seismology and earthquake hazard mitigation, Nature (London), 390, 461-464.

Karato, S. (1993), Importance of anelasticity in the interpretation of seismic tomography, Geophys. Res. Lett., 20, 1623-1626.

Karato, S., and H. A. Spetzler (1990), Defect microdynamics in minerals and solid-state mechanisms of seismic wave attenuation and velocity dispersion in the mantle, Rev. Geophys., 28, 399-421.

Lawrence, J. F., and M. E. Wysession (2006), QLM9; a new radial quality factor $(Q(\mathrm{sub} \mathrm{mu}))$ model for the lower mantle, Earth Planet. Sci. Lett., 241, 962-971.

Lawrence, J. F., P. M. Shearer, and G. Masters (2006), Mapping attenuation beneath North America using waveform cross-correlation and cluster analysis, Geophys. Res. Lett., 33, L07315, doi:10.1029/2006GL025813.

Lay, T., and D. V. Helmberger (1981), Body wave amplitude patterns and upper mantle attenuation variations across North America, Geophys. J. R. Astron. Soc., 66, 691-726.

Lay, T., and T. C. Wallace (1988), Multiple ScS attenuation and travel times beneath western North America, Bull. Seismol. Soc. Am., 78, 2041-2061.

Lee, C.-T. A. (2003), Compositional variation of density and seismic velocities in natural peridotites at STP conditions: Implications for seismic imaging of compositional heterogeneities in the upper mantle, J. Geophys. Res., 108(B9), 2441, doi:10.1029/2003JB002413. 
Lees, J. M., and J. Park (1995), Multiple-taper spectral analysis; a standalone C-subroutine, Comput. Geosci., 21, 199-236.

Marone, F., and B. Romanowicz (2007), Non-linear crustal corrections in high-resolution regional waveform seismic tomography, Geophys. J. Int., $170,460-467$.

Melbourne, T., and D. V. Helmberger (1998), Fine structure of the 410-km discontinuity, J. Geophys. Res., 103, 10,091-10,102.

Mitchell, B. J. (1975), Regional Rayleigh wave attenuation in North America, J. Geophys. Res., 80, 4904-4916.

Mitchell, B. J., and L. Cong (1998), Lg coda $Q$ and its relation to the structure and evolution of continents; a global perspective, Pure Appl. Geophys., 153, 655-663.

Morgan, P., and W. D. Gosnold (1989), Heat flow and thermal regimes in the continental United States, Mem. Geol. Soc. Am., 172, 493-522.

Perry, H. K. C., A. M. Forte, and D. W. S. Eaton (2003), Uppermantle thermochemical structure below North America from seismicgeodynamic flow models, Geophys. J. Int., 154, 279-299.

Pollack, H. P., S. J. Hurter, and J. R. Johnson (1993), Heat flow from the Earth's interior: Analysis of the global data set, Rev. Geophys., 31, $267-$ 280 .

Priestley, K., and D. McKenzie (2006), The thermal structure of the lithosphere from shear wave velocities, Earth Planet. Sci. Lett., 244, $285-$ 301.

Reid, F. J. L., J. H. Woodhouse, and H. J. van Heijst (2001), Upper mantle attenuation and velocity structure from measurements of differential S phases, Geophys. J. Int., 145, 615-630.

Romanowicz, B. (1995), A global tomographic model of shear attenuation in the upper mantle, J. Geophys. Res., 100, 12,375-12,394.

Romanowicz, B. (2008), Using seismic waves to image Earth's internal structure, Nature, 451, 266-268.

Romanowicz, B., and Y. C. Gung (2002), Superplumes from the coremantle boundary to the lithosphere: Implications for heat flux, Science, 296, 513-516.

Romanowicz, B., D. E. Byrne, and S. K. Singh (1993), The Berkeley digital seismic network; upgrade status, Seismol. Res. Lett., 64, 42.

Sato, H., I. Sacks, and T. Murase (1989), The use of laboratory velocity data for estimating temperature and partial melt fraction in the low-velocity zone: Comparison with heat flow and electrical conductivity studies, J. Geophys. Res., 94, 5689-5704.

Schutt, D. L., and C. E. Lesher (2006), Effects of melt depletion on the density and seismic velocity of garnet and spinel lherzolite, J. Geophys. Res., 111, B05401, doi:10.1029/2003JB002950.
Secor, D. T., Jr., A. W. Snoke, and R. D. Dallmeyer (1986), Character of the Alleghanian Orogeny in the Southern Appalachians: Part III. Regional tectonic relations, Geol. Soc. Am. Bull., 97, 1345-1353.

Selby, N. D., and J. H. Woodhouse (2002), The $Q$ structure of the upper mantle: Constraints from Rayleigh wave amplitudes, J. Geophys. Res., 107(B5), 2097, doi:10.1029/2001JB000257.

Shapiro, N. M., and M. H. Ritzwoller (2004), Inferring surface heat flux distributions guided by a global seismic model: Particular application to Antarctica, Earth Planet. Sci. Lett., 223, 213-224.

Sobolev, S. V., S. V. H. Zeyen, G. Stoll, F. Werling, R. Altherr, and K. Fuch (1996), Upper mantle temperatures from teleseismic tomography of French Massif Central including effects of composition, mineral reactions, anharmonicity, anelasticity and partial melt, Earth Planet. Sci. Lett., 139, 147-163.

Solomon, S. C., and M. N. Toksöz (1970), Lateral variation of attenuation of $\mathrm{P}$ and $\mathrm{S}$ waves beneath the United States, Bull. Seismol. Soc. Am., 60, $819-838$.

Stein, S., and M. Wysession (2003), An Introduction to Seismology, Earthquakes, and Earth Structure, Blackwell, Malden, Mass.

Teng, T.-L. (1968), Attenuation of body waves and the $Q$ structure of the mantle, J. Geophys. Res., 73, 2195-2208.

Trampert, J., H. Paulssen, A. van Wettum, J. Ritsema, R. Clayton, R. Castro, C. Rebollar, and A. Perez-Vertti (2003), New array monitors seismic activity near the Gulf of California in Mexico, Eos Trans. AGU, 84, 29.

Van der Lee, S. (2002), High-resolution estimates of lithospheric thickness from Missouri to Massachusetts, USA, Earth Planet. Sci. Lett., 203, 15-23.

Van der Lee, S., and G. Nolet (1997), Upper mantle S velocity structure of North America, J. Geophys. Res., 102, 22,815-22,838.

Warren, L. M., and P. M. Shearer (2002), Mapping lateral variations in upper mantle attenuation by stacking $P$ and $P P$ spectra, $J$. Geophys. Res., 107(B12), 2342, doi:10.1029/2001JB001195.

Yamazaki, D., and S.-i. Karato (2001), Some mineral physics constraints on the rheology and geothermal structure of Earth's lower mantle, Am. Mineral., 86, 385-391.

Yang, Y., D. W. Forsyth, and D. S. Weeraratne (2007), Seismic attenuation near the East Pacific Rise and the origin of the low-velocity zone, Earth Planet. Sci. Lett., 258, 260-268.

S. Goes, Department of Earth Science and Engineering, Imperial College London, London SW7 2AZ, UK.

Y. K. Hwang and J. Ritsema, Department of Geological Sciences, University of Michigan, 2534 C. C. Little Building, 1100 North University Avenue, Ann Arbor, MI 48109-1005, USA. (ykhwang@umich.edu) 